www.jmscr.igmpublication.org

Impact Factor 5.244

Index Copernicus Value: 83.27

ISSN (e)-2347-176x ISSN (p) 2455-0450

crossref DOI: _http://dx.doi.org/10.18535/jmscr/v4i10.20

\title{
The Efficacy of Infliximab plus Methotrexate in Patients with Active Rheumatoid Arthritis in North of Iraq: 5-Year Extended Study
}

\author{
Author \\ Dr Niaz Al-Barzinji \\ Consultant Rheumatologist \\ Iraq- Erbil \\ Hawler Medical University/College of Medicine
}

\begin{abstract}
Objective: To evaluate the role of infliximab plus methotrexate given for up to 5 years in patients with active longstanding rheumatoid arthritis.

Methods: patients responding inadequately to methotrexate and at least one other disease-modifying antirheumatic drug were enrolled into a 24 week, controlled study with infliximab plus methotrexate or placebo plus methotrexate and some were enrolled in a subsequent open label extension. The efficacy were evaluated.

Results: Among 250 patients in the original trial, 220 received at least one dose of infliximab and were evaluated. At the time of analysis 160/ 220 (72.7\%) patients had remained in the study and received treatment for a mean of 4.5 years. Withdrawals were for lack of efficacy (24\%), adverse events (36\%), and other reasons(50\%). In 160 patients who completed 5 years treatment efficacy achieved of 6 month was maintained at 5 years. $45 \%$ achieved clinical remission (DAS28<2.6), and $27 \%$ had no physical function abnormalities $(H A Q=0)$. Results were similar for 160 patients who received treatment for 3-5 years.

Conclusions: Infliximab plus methotrexate sustained clinical response and remission in patients with rheumatoid arthritis during 5 years
\end{abstract}

\section{Introduction}

Rheumatoid arthritis is a chronic inflammatory autoimmune disease of unknown etiology that occurs in approximately $0.8 \%$ of population. ${ }^{1}$ although the pathophysiology of rheumatoid rheumatoid arthritis is not completely understood ,tumor necrosis factor (TNF) a proinflammatory cytokine, appears to have a key role in its aetiology ${ }^{1,2}$. Use of TNF antagonists as a highly effective and targeted therapeutic strategy that directly alters the biological processes underlying rheumatoid arthritis synovial inflammation and progressive structural destruction. ${ }^{3,4}$ Infliximab is a monoclonal antibody that binds with high affinity and specificity to human TNF and neutralizes its biologic activity5

\section{Patients and Methods}

Patients were eligible to enroll in the randomized, controlled trial if they were aged $>18$ years, met ACR criteria for the diagnosis of rheumatoid arthritis, ${ }^{6}$ and had at least nine tender joints and six swollen joints. patients were required to have been treated with methotrexate and at least one 
other disease modifying anti-rheumatic drugs for a minimum of 6 months before screening and to have been receiving a stable weekly dose of 12.5$25 \mathrm{mg} /$ week for at least 8 weeks before screening. During the 6 months, blinded trial, patients were randomized to receive either placebo or infliximab at dose of $3 \mathrm{mg} / \mathrm{kg}$ body weight at weeks 0,2 and 6, then every 8 weeks. Methotrexate and corticosteroid doses and routs of administration were required to remain unchanged. Once patients completed the 24 weeks, blinded portion of the trial. All patients (including those originally receiving placebo) were permitted to enter an open label extension study and receive the standard infiliximab dose in combination with methotrexate. In addition patients whether they had received infliximab or placebo who had failed to achieve clinical improvement at or after 16 weeks in the blinded trial could enter the open label extension at that time. Efficacy outcomes were regularly evaluated and assessed as observed data. Baseline values for the patients group analyzed in this study reflects the values at entry of patients randomized to either placebo or infliximab in the controlled period of the trial. Consequently, changes from baseline in the efficacy were measured by using clinical evaluations on the 28 joint count disease activity score (DAS28) using $\mathrm{C}$ reactive protein(CRP) based formula, useful for continual assessments of efficacy. 7 a DAS28 cut off value $<2,6$ was used to define clinical remission based on published sensitivity and specificity analysis in clinical setting. 8 physical function was evaluated by measuring changes in the disability index of the health assessment questionnaire (HAQ).

Patients who had remained in the study and had completed visit (visit every 3months) reports within pre specified frames since study entry were analyzed. A paired t test was employed to detect statistically significant difference in disease activity and functional outcomes from baseline in patients available for analyses at 5 years.

\section{Results}

A total of 220 patients were randomized into the trial and 160 patients completed 24 weeks. All patients completing weeks 24 , including those in the placebo arm, as well as any patients who failed to meet or maintain an DAS28 response at week 16 , were eligible to roll over into an open label extension study. ${ }^{9}$ All patients received the standard dose of infliximab $3 \mathrm{mg} / \mathrm{kg} 0,2$ weeks then 6week and then every 8 week of 220 patients originally enrolled in this study $60(27.27 \%)$ of them withdrew from the study, among the 60 patients who withdrew from the study, 12(24\%) withdrew for lack of efficacy, 18(36\%) for adverse side effects and 30 (50\%) for other reasons. The mean age of all 220 patients treated with infliximab and evaluated in this study was 55 years and the majority were women (75\%) table (1). The mean duration of disease was 12.4 years. Baseline mean tender joint count (TJC), swollen joint count (SJC) and HAQ values were all indicative of significant disease activity, which occurred despite previous use of various antirheumatic drugs. At the time of enrolment the majority of patients (74\%) had been treated previously with two or three traditional disease modifying drugs, including methotrexate. The demographic and baseline disease characteristics (TJC, SJC, HAQ, CRP and DAS28) of the 160 patients who had reached 5 years of treatment (table 2). These patients showed a statistically significant reduction of mean TJC by more than $70 \%$, while mean SJC and DAS28 score had decreased by $40-60 \%$ compared with baseline values. the mean HAQ was 0.7 among these patients, indicative of a significantly improved physical functioning status v base line table (2).

Similarly, results for the 160 patients who had 3-5 years treatment with infliximab confirmed that clinical benefits achieved during the 1st 6 months of treatment, either in the blinded period of the study or in the first 6 months of the open label trial for patients originally receiving placebo, were sustained with infilximab treatment throughout the continuation study. 
The percentage of patients who had achieved clinical remission using the DAS $28<2.6$ criterion. 19,23 were $32 \%$ at 6 months and $43 \%$ at 5 years .mean DAS28 had declined from 5.8 at base line to 3.3 at 6 months of treatment and 3.2, 3.1, 3.1, 3.0 and 3 at years 1,2,3,4,5, respectively. Mean CRP concentration had decreased from $25 \mathrm{mg} / \mathrm{l}$ at base line to $7 \mathrm{mg} / \mathrm{l}$ after 1 year of continuous treatment, indicative normalization in this biomarker of systemic inflammation. This reduction was sustained in patients who received infliximab from 2 through 5 years. as shown by CRP concentrations $<10 \mathrm{mg} / \mathrm{l}$. In addition reductions in the mean TJC and SJC were seen at 6 months of treatment and sustained over time in completers. The reduction seen in TJC was from a mean of 28.1 at baseline to 8.3 joints at years 1 through 5 . Mean SJC had declined from 17.7 affected joints to 5.4 joints at years 1 through 5. During the first 6 months of treatment, the mean HAQ score had decreased from 1.5 to 0.8 . this improvement was sustained for up to 5 years, with a HAQ score of 0.8 at years 1 through 3 and a score of 0.7 at year 5. this mean $80-82 \%$ achieved a clinically meaningful improvement in their HAQ score > 0.22).24 and $19-27 \%$ of patients had reached and sustained a completely normal physical function status while receiving infliximab treatment, assessed by a HAQ score of 0 table (3).

Table (1) baseline disease characteristics of patients with rheumatoid arthritis who received infliximab at any time during the blinded period or open label extension study $n=160$

\begin{tabular}{|c|c|c|}
\hline Characteristics & Value & Range \\
\hline Age & $55(11.8)$ & $25-74$ \\
\hline Female(\%) & 75 & \\
\hline Disease duration(years) & $12.4(9,5)$ & $0.33-56.92$ \\
\hline Tender joint count( $0-68$ joints $)$ & $28.4(14.2)$ & $9-65$ \\
\hline Swollen joint count (0-68 joints) & $17.2(8.6)$ & $6-43$ \\
\hline Patients global assessment of pain(0-100)mm VAS & $52.6(23)$ & $0-99$ \\
\hline Patients global assessment of disease activity(0-100) mm VAS & $55.6(23.5)$ & $0-99$ \\
\hline HAQ disability index (0-3 scale) & $1.55(0.62)$ & $0.1-2.7$ \\
\hline DAS 28 & $5.8(1.0)$ & $2.9-8.1$ \\
\hline $\mathrm{C}$ reactive protein $(\mathrm{mg} / \mathrm{l})$ normal $<10$ & $25(23)$ & $0.5-165$ \\
\hline Number of previous DMARDs (mean) & 2 & $1-3$ \\
\hline
\end{tabular}

Values are mean (SD), the (VAS) for pain ranges from $0=$ no pain to $100=$ severe pain, VAS for disease activity ranges from $0=$ no disease activity to $100=$ extreme disease activity, the health assessment Questionnaire (HAQ) scale range from $0=$ no difficulty to $3=$ unable to perform activity. DAS28 is based on a 28 joint assessment for pain, swelling using the CRP based formula.

Table (2) shows the efficacy assessment of patients with rheumatoid arthritis in the closed and open label extension who completed 5 years of continuous treatment with infliximab.

\begin{tabular}{|l|c|c|c|c|}
\hline Criterion & Baseline & 5 years & Absolute change & Percentage change \\
\hline Tender joint count $(0-68)$ & $28.1(13.8)$ & $8.3(12.5)$ & $-19.7(13.8)$ & -70.8 \\
\hline Swollen joint count $(0-68)$ & $17.7(8.6)$ & $5.4(6.7)$ & $-12.3(10.8)$ & -60.7 \\
\hline HAQ $(0-3)$ & $1.5(0.6)$ & $0.8(0.7)$ & $-0.7(0.6)$ & -52.1 \\
\hline CRP $(\mathrm{mg} / \mathrm{l})$ (normal<10mg/l) & $25(23)$ & $7(12)$ & $-18(23)$ & -58 \\
\hline DAS28 (remission<2.6) & $5.8(0.9)$ & $3.0(1.2)$ & $-2.7(1.4)$ & -46.5 \\
\hline
\end{tabular}

results are shown as mean (SD) of each individual patient result for each criterion, values for absolute change and percentage changes from baseline are based on actual data from patients of 5 years ( $\mathrm{n}=160$ patients) had TJC, SJC, and CRP data available ,A negative absolute or percentage change indicates an improvement in the response criterion.

$\mathrm{p}<0.001$ paired $\mathrm{t}$ test (last result compared with baseline). 
Table (3) $\mathrm{No}(\%)$ patients with rheumatoid arthritis during the study with no signs of joint involvement (TJC=0, SJC $=0$ ), normal CRP $<10$, clinical remission based on DAS28 $<2.6$ and normal functional status( $\mathrm{HAQ}=0$ ).

\begin{tabular}{|l|c|c|c|c|c|c|}
\hline \multirow{2}{*}{ Variables } & \multicolumn{6}{|c|}{ Month } \\
\cline { 2 - 7 } & $\mathbf{6}$ & $\mathbf{1 2}$ & $\mathbf{2 4}$ & $\mathbf{3 6}$ & $\mathbf{4 8}$ & $\mathbf{6 0}$ \\
\hline TJC $=0$ & $40(25)$ & $36(22.5)$ & $48(30)$ & $43(26.87)$ & $42(26.25)$ & $47(29.37)$ \\
\hline SJC $=0$ & $33(20.62)$ & $37(23.12)$ & $52(32.5)$ & $42(26.25)$ & $39(24.37)$ & $46(28.75)$ \\
\hline CRP $<10 \mathrm{mg} / 1$ & $146(91.25)$ & $141(88.12)$ & $144(90)$ & $149(93.12)$ & $127(79.37)$ & $139(86.87)$ \\
\hline DAS $<2.6$ & $51(32)$ & $63(39.37)$ & $72(45)$ & $69(43.12)$ & $76(47.5)$ & $68(43)$ \\
\hline HAQ $=0$ & $31(19.37)$ & $34(21.25)$ & $38(23.75)$ & $41(25.62)$ & $40(25)$ & $44(27.5)$ \\
\hline
\end{tabular}

\section{Discussion}

The present study demonstrated that the majority of patients with longstanding rheumatoid arthritis who had continued to receive the standard treatment of infliximab plus methotrexate for up to 5 years experienced significant, sustained improvement in sign and symptoms, disease activity, and functional status. the results of this study are consistent with those seen in patients treated with etanercept in combination with methotrexate for 3 years. ${ }^{9}$ Although methotrexate is considered the anchor drug of rheumatoid arthritis treatment, in some studies methotrexate monotherapy may lead to decreased efficacy and reduced patients compliance over time. ${ }^{10-13}$ on the other hand the long term efficacy observed when methotrexate is combined with a TNF antagonist may lead to sustained patient compliance. in randomised studies, initiation of a TNF antagonist in combination with methotrexate has showen the combination to be more efficious than either methotrexate ${ }^{8,10,11,14}$ or TNF antagosist as monotherapy, ${ }^{6-13,15-25}$ without being necessarily more toxic.

The reduction of HAQ to an average mean score of $0.7-0.8$ for up to 5 years seen in this study is important for the long term prognosis of these patients. Although functional improvements achieved with TNF antagonists mostly depend on baseline joint destruction in individual patients, ${ }^{26}$ the direct correlation between physical function and radiographic progression is stronger for patients with longstanding, active rheumatoid arthritis than for patients in the early stages of the disease. $^{27}$ the functional improvements seen in this study need to be complemented with studies confirming long term inhibition of radiographic progression in patients with longstanding rheumatoid arthritis.

\section{Conclusion}

The majority of patients with rheumatoid arthritis who entered this study of infliximab in combination with methotrexate achieved substantial improvement in disease activity, including improvement in swollen and tender joints, global assessment of disease activity, functional status, and CRP concentration. These improvements were sustained for 5 years, with many patients achieving clinical remission and functional normality with continuous infliximab treatment. To acquire even longer term information about drug response and tolerability, these patients with rheumatoid arthritis will need continuous follow up over time.

\section{References}

1. Choy E, Panayi G. Cytokine pathways and joint inflammation in rheumatoid arthritis. N Engl J Med 2001; 344:907-16.

2. Lee D, Weinblatt M. Rheumatoid arthritis. Lancet 2001; 358:903-11.

3. O'Dell J. Therapeutic strategies for rheumatoid arthritis. N Engl J Med 2004; 350:2591-602.

4. Furst DE, Breedveld FC, Kalden JR, Smolen JS, Burmesler GR, Bijlsma JW, et al. Updated concensus statement on biological agents, specifically tumor necrosis factor $\alpha$ (TNF $\alpha)$ blocking agents and interleukin-1 receptor antagonists (IL-1ra), for the treatment of rheumatic diseases, 
2005. Ann Rheum Dis 2005; 64(suppl IV): iv 2-14.

5. Lipsky P, van der heijde D, St Clair E, Furst DE, Breedveld FC, Kalden JR, et al. Infliximab and methotrexate in the treatment of rheumatoid arthritis: anti tumor necrosis factor trial in rheumatoid arthritis with concomitant therapy group. N Engl J Med 2000; 343:1594-602.

6. Arnett F, Edwarthy S, Bloch D, McShane DJ, Fries JF, Cooper NS, et al. The American Rheumatism Association 1987revised criteria for the classification of rheumatoid arthritis. Arthritis Rheum 1988;31:315-24.

7. Prevoo M, van $\mathrm{T}$ Hof $M$, Kuper $H$, van Leeuwent, M, van de Putte L, Riel P. Modified disease activity scores that include twenty-eight-joint counts. Arthritis Rheum 1995;38:44-8.

8. Prevoo M, van T Hof M, van Gestel A, van Rijiswik M, van de Putte L, Riel P. Remission in a prospective study of patients with rheumatoid arthritis. American Rheumatism Association preliminary remission criteria in relation to the disease activity score. $\mathrm{Br}$ J Rheumatolo 1996;35: 1101-5.

9. Kremer J, Weinblatt M, Bankhurst A, Bulpitt KJ, Fleischmann RM, Jackson CG, et al. Etanercept added to background methotrexate therapy in patients with rheumatoid arthritis. Continued observation. Arthritis Rheum 2003;6;1493-9.

10. Weinblatt M. Rheumatoid arthritis in 2003: where are we now with treatment? Ann Rheum Dis 2003;63(suppl 2): 1194-6.

11. Wolfe F, Rehman Q, Lane N, Kremer J. Starting a disease modifying antirheumatic drug or a biologic agent in rheumatoid arthritis: standards of practice for RA treatment. J Rheumatol 2001;28:1704-11

12. Lambert C, Sandhu S, Lachhead A, Hurst NP, McRorie E, Dhillon V. Dose escalation of parenteral methotrexate in active rheumatoid arthritis that has been unresponsive to conventional doses of methotrexate. A randomized, controlled trial. Arthritis Rheum 2004;50:364-71.

13. O'Dell J, Haire C, Erikson N, Drymalski W, Palmer W, Eckhoff PJ, et al. Treatment of rheumatoid arthritis with methotrexate alone, sulasalazine and hydroxychloroquine or a combination of all three medications. N Engl J Med 1996;334:1287-91.

14. Keystone E, Kavanaugh A, Sharp J, Tannenbaum H, Hua Y, Teoh LS, et al. Radiographic, clinical and functional outcomes of treatment with adalimimab ( a human anti-tumor necrosis factor monoclonal antibody). in patients with active rheumatoid arthritis receiving concomitant methotrexate therapy. Arthritis Rheum 2004;50:1400-11.

15. Maini R, Breeveld F, Kalden J, Smolen JS, Furst D, Weisman MH, et al. Sustained improvement over two years in physical function, structural damage and signs and symptoms among patients with rheumatoid arthritis treated with infliximab and methotrexate. Arthritis Rheum 2004; 50:1051-65.

16. St Clair E, Desiree M, van der Heijda D, Maini RN, Bathon JM, Emery $\mathrm{P}$, et al. Combination of infliximab and methotrexate therapy for early rheumatoid arthritis. Arthritis Rheum 2004;50:3432-43.

17. Weinblall M, Kremer J, Bankhurst A, Bulpitt KJ, Fleischmann RM, Fox RI, et al. A trial of etanercept, a recombinant tumor necrosis factor receptor Fc fusion protein, in patients with rheumatoid arthritis receiving methotrexate. $N$ Engl $J$ Med 1999;340:253-9.

18. Klareskog L, van der Heijda D, de Jager J, Gough A, Kalden A, Malaise M, et al. Therapeutic effect of the combination of etanercept and methotrexate compared with each treatment alone in patients with rheumatoid arthritis: double blind 
randomized controlled trial. Lancet 2004;363:675-81.

19. Genovese M, Bathon J, Martin R, Fleischmann RM, Tesser JR, Schiff MH, et al. Etanercept versus methotrexate in patients with early rheumatoid arthritis: two years radiographical and clinical outcomes. Arthritis Rheum 2002;46:1443-50.

20. Moreland LW, Cohen SB, Baumgartner SW, Tindall EA, Bulpitt K, Martin R, et al. Long-term safety and efficacy of etanercept in patients with rheumatoid arthritis. J Rheumatol 2001;28:1238-44.

21. Felson DT, Edwarthy S, Bloch D, McShane DJ, Fries JF, Cooper NS, et al. American College of Rheumatology preliminary definition of improvement in rheumatoid arthritis. Arthritis Rheum 1995;38:727-35.

22. Lubeck D. Health-related quality of life measurements and studies in rheumatoid arthritis. Am J Manag Care 2002;8:81120.

23. Surveillance, Epidemiology and End Results (SEER) Program Public-Use Data Program, Cancer Statistics Branch, released April 2002, based on the November 2001 submission.

24. Balsa A, Carmona L, Gonzalez-Alvaro I, Belmonte MA, Tena X, Sammarti R. Value of disease Activity Score 28 (DAS28) and DAS28-3 compared to American College of Rheumatologydefined remission in rheumatoid arthritis. $J$ Rheumatol 2004;31:40-6.

25. Goldsmith $\mathrm{CH}$, Boers $\mathrm{M}$, Bambardier C, Tugwell P. Criteria for clinically important changes in outcomes: development, scoring and evaluation of rheumatoid arthritis patient and trial profiles. OMERACT Committee. J Rheumatol 1993;20:561-5.
26. Breedveld F, Han C, Bala M, van der Heijda D, Baker D, Kavanaugh AF, et al. Association between baseline radiographic damage and improvement in physical function after treatment of patients with rheumatoid arthritis. Ann Rheum Dis 2005;64:52-5.

27. Doran M, Crowson C, Pond G, O'Fallon $\mathrm{W}$, Gabriel S. Frequency of infection in patients with rheumatoid arthritis compareed with controls: a population-based study. Arthritis Rheum 2002;46:2287-93. 